\title{
MELAKSANAKAN PROGRAM KERJA PENDIDIKAN DAN PELATIHAN BERDASARKAN DENGAN KEBUTUHAN MASYARAKAT DI DESA TAPOS 2
}

\author{
Ahmad Mulyadi Kosim ${ }^{1}$, Andry Kurniawan, Anita Rahayu ${ }^{2}$ \\ ahmadmulyadi@fai.uika-bogor.ac.id \\ Dosen Fakultas Agama Islam ${ }^{1}$, Mahasiswa KKN Kelompok 07 Tahun $2018^{2}$
}

\begin{abstract}
ABSTRAK
Kuliah Kerja Nyata atau KKN adalah sebuah program pengabdian kepada masyarakat yang dilaksanakan di daerah tertentu yang berguna untuk membantu masyarakat dalam bidang fisik maupun nonfisik. Desa Tapos 2 kecamatan Tenjolaya Bogor merupakan salah satu wilayah yang dipilih dan ditunjuk LPPM untuk menjadi tempat menjalankan program kuliah kerja nyata yang bertemakan tematik terintegrasi. Banyaknya masyarakat Desa Tapos 2 yang memandang bahwa pendidikan itu merupakan sesuatu yang mahal dan tidak harus dilanjutkan hingga ke tingkat yang lebih tinggi seperti perguruan tinggi, Hal itu berdampak pada sedikitnya pemberdayaan masyarakat dalam menunjang ekonomi Desa Tapos 2. Khususnya untuk ibu-ibu rumah tangga yang tidak memiliki usaha sampingan. Kemudian akhirnya kami membuat penyuluhan dan pelatihan UMKM. Maka dari itu kami mencetuskan sebuah tema "Melaksanakan Program Kerja Pendidikan Dan Pelatihan Berdasarkan Dengan Kebutuhan Masyarakat di Desa Tapos 2" yang diharapkan dapat mengatasi masalah desa sedikit demi sedikit
\end{abstract}

Kata Kunci: Pendidikan, UMKM, Pemberdayaan Masyarakat, Tapos 2.

\section{PENDAHULUAN}

Desa Tapos 2 kecamatan Tenjolaya merupakan salah satu tempat yang dipilih oleh LPPM untuk menjadi tempat pelaksanaan kuliah kerja nyata yang bertemakan tematik terintegrasi. Anggota kelompok 7 berjumlah 14 orang yang terdiri dari fakultas dan jurusan yang berbedabeda.

Berdasarkan hasil survey yang dilakukan di Desa Tapos 2, di pilih satu kampung yaitu Tapos Lebak dengan sasaran RW 04 yang terdiri dari 3 RT. Desa Tapos 2 dan kampung Tapos Lebak mempunyai masyarakat yang karakteristik yang beragam, sehingga dalam penyusunan serta perancangan suatu program disesuaikan dengan kondisi, situasi dan potensi yang dimiliki oleh masyarakat setempat.

Setelah dilakukan survey oleh anggota KKN kelompok 7 dapat dilihat kondisi masyarakat di Desa Tapos 2 cukup produktif khususnya dibidang pertanian, sedangkan bidang yang masih belum produktif ada dibidang industri. Oleh karena itu kami memilih untuk melaksanakan program yang mencangkup 4 pilar utama yaitu, Pendidikan, Ekonomi, Lingkungan dan Kesehatan. 


\section{Keadaan Geografis}

Desa Tapos 2 merupakan salah satu Desa di wilayah kecamatan Tenjolaya Kabupaten Bogor, dengan luas wilayah sebagaii berikut:

\begin{tabular}{|l|l|}
\hline \multicolumn{1}{|c|}{ Lahan } & \multicolumn{1}{c|}{ Luas } \\
\hline Darat & $65.000 \mathrm{Ha}$ \\
\hline Sawah & $162.17 \mathrm{Ha}$ \\
\hline $\begin{array}{l}\text { Lahan } \\
\text { Pemukiman }\end{array}$ & $55.000 \mathrm{Ha}$ \\
\hline Lahan Pertanian & $172.17 \mathrm{Ha}$ \\
\hline
\end{tabular}

Desa Tapos terdiri dari 5 (Lima) Dusun, 8 (Delapan) RW dan 23 (Dua puluh tiga) RT. Batas Wilayah Desa Tapos 2 adalah sebagai berikut:

\begin{tabular}{|l|l|}
\hline \multicolumn{1}{|c|}{ Arah } & \multicolumn{1}{c|}{ Berbatasan } \\
\hline Utara & Desa Cibitung Tengah \\
\hline Selatan & Desa Tapos 1 \\
\hline Barat & $\begin{array}{l}\text { Desa Cibening/ Gn. } \\
\text { Bunder }\end{array}$ \\
\hline Timur & $\begin{array}{l}\text { Desa Gunung } \\
\text { Malang/Gn. Mulya }\end{array}$ \\
\hline
\end{tabular}

\section{Kondisi Masyarakat}

Jumlah pendudukan Desa Tapos 2 pada akhir bulan agustus 2018 sebagai berikut ini:

\begin{tabular}{|l|l|}
\hline \multicolumn{1}{|c|}{ Jumlah Penduduk } & Jumlah \\
\hline Laki-laki & 4.365 Orang \\
\hline Perempuan & 4.080 Orang \\
\hline Jumlah KK & 2.189 Orang \\
\hline
\end{tabular}

Dan berikut ini adalah jumlah penduduk Desa Tapos 2 bedasarkan usia:

\begin{tabular}{|l|c|}
\hline Jumlah Penduduk & Jumlah \\
\hline 00-04 Thn & 949 Orang \\
\hline 05-09 Thn & 882 Orang \\
\hline 10-14 Thn & 987 Orang \\
\hline 15-19 Thn & 962 Orang \\
\hline
\end{tabular}

\begin{tabular}{|l|l|}
\hline 20-24 Thn & 1353 Orang \\
\hline 25 Thn ke atas & 3312 Orang \\
\hline
\end{tabular}

Berkaitan untuk masalah keamanan dan ketertiban, dapat dikatakan Desa Tapos 2 cukup aman, dikarenakan adanya organisasi Perlindungan Masayarakat (LINMAS). Sampai saat ini jumlah anggota tercatat sebanyak 12 Orang.

\section{Bidang Ekonomi}

Mayoritas masyarakat di Desa Tapos 2 adalah seorang peternak dan buruh tani. Berikut data luas pertanian yang terdapat di Desa Tapos 2:

$$
\begin{array}{lll}
\text { - } & \text { Padi } & : 15 \mathrm{Ha} \\
\text { - } & \text { Jagung } & : 5 \mathrm{Ha} \\
\text { - } & \text { Ketela Pohon }: 18 \mathrm{Ha} \\
\text { - } & \text { Ketela Rambat }: 30 \mathrm{Ha}
\end{array}
$$

\section{Bidang Pendidikan}

Desa Tapos 2 memiliki 6 gedung Paud yang dilaksanakan dari hari Senin Jum'at, 4 gedung TK/TPQ, 5 gedung SD/MI, 3 gedung SLTP / Sederajat, 3 gedung SLTA / Sederajat dan 9 Pondok Pesantren.

\section{Bidang Kesehatan}

Pelayanan bidang kesehatan yang ada di Desa Tapos 2 yakni Posyandu, diselenggarakan setiap 1 bulan satu kali.

\section{Bidang Olahraga}

Pada bidang ini, Ibu-ibu PKK selalu mengadakan senam sehat yang dilaksanakan seminggu 2 kali pada hari Kamis dan Minggu, biasanya senam sehat dilakukan dihalaman SDN Tapos 2. 


\section{METODE PENGABDIAN}

\section{Tahap pelaksanaan}

Berikut ini adalah tahapan pelaksanaan untuk program pelatihan dan penyuluhan UMK

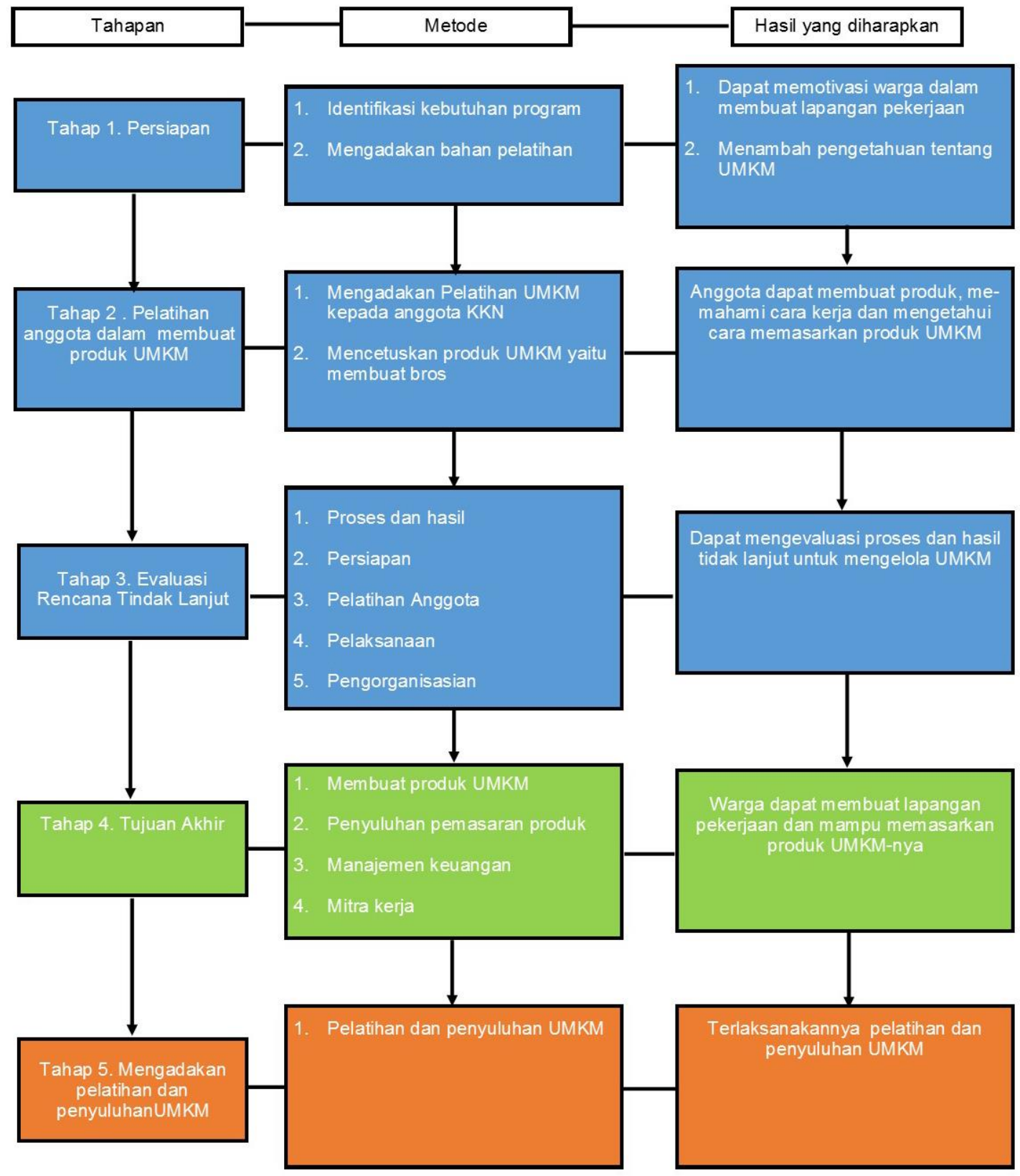

\section{Metode pendekatan}

Pemberdayaan masyarakat adalah suatu proses yang mengembangkan dan memperkuat kemampuan masyarakat untuk terus terlibat dalam proses pembangunan yang berlangsung secara dinamis sehingga masyarakat dapat menyelesaikan masalah yang dihadapi serta dapat mengambil keputusan secara bebas (independent) dan mandiri (Oakley, 1991; dan Fatterman, 1996). Proses pemberdayaan masyarakat merupakan upaya membantu masyarakat untuk mengembangkan kemampuannya sendiri sehingga bebas dan mampu untuk mengatasi masalah dan mengambil keputusan secara mandiri. Proses pemberdayaan tersebut dilakukan dengan memberikan kewenangan (power), 
aksesibilitas terhadap sumberdaya dan lingkungan yang akomodatif (Zimmerman, 1996:18, Ress, 1991:42).

Maka dari itu metode pemberdayaan masyarakat yang dijalankan oleh kami ada metode participatory rural appraisal (PRA).

PRA adalah suatu metode pendekatan untuk mempelajari kondisi dan kehidupan pedesaan dari, dengan, dan oleh masyarakat desa. Atau dengan kata lain dapat disebut sebagai kelompok metode pendekatan yang memungkinkan masyarakat desa untuk saling berbagi, meningkatkan, dan menganalisis pengetahuan mereka tentang kondisi dan kehidupan desa, membuat rencana dan bertindak (Chambers, 1996).

\section{REALISASI PROGRAM}

Kuliah Kerja Nyata (KKN) dilaksanakan pada tanggal 7 Agustus 2018 sampai 5 September 2018, sebelum kegiatan tersebut terlaksana telah dilakukan serangkaian persiapan untuk mendukung terlaksananya program kerja KKN. Serangkaian persiapan antara lain: melakukan observasi ke wilayah sasaran yang dilakukan sebanyak satu kali, yaitu pada tanggal 31 Juli 2018 atau 1 Agustus 2018 kegiatan tersebut meliputi observasi fisik dan nonfisik desa.

Adapun pembekalan KKN yang dihadiri oleh ketua kelompok sebagai perwakilan kelompok pada tanggal 30 Juli 2018 yang dilakukan oleh pihak LPPM dengan penyampaian materi tentang pemberdayaan masyarakat melalui $\mathrm{KKN}$, materi tentang Training of Trainer (TOT) terkait dengan teknis kegiatan KKN.

Setelah melaksanaka pendataan dan observasi desa, baik dari segi fisik maupun nonfisik, selanjutnya merumuskan progra- program kerja yang sesuai, melakukan koordinasi dan tindak lanjut pada Dosen Pembimbing Lapangan (DPL), Kepala Desa Tapos 2 dan pihak masyarakat yang berkaitan dengan pelaksanaan kegiatan KKN. Berikut beberapa rencana program kerja kelompok 07, antara lain:

\section{Program Non-Fisik}

a. Penyuluhan PHBS (Cuci Tangan) Kegiatan ini dilaksanakan guna memperkenalkan bagaimana cara hidup sehat khususnya pada anakanak. Kita harus mengenalkan cara hidup sehat sejak dini supaya bisa menjadi kebiasaan yang kemudian mereka terapkan dikehidupan sehari-hari sampai mereka besar.

b. Penyuluhan Polisi Sahabat Anak

Kegiatan ini dilakukan guna menanamkan rasa kecintaan anakanak terhadap polisi sehingga mereka merasa aman, nyaman dan tidak takut lagi terhadap polisi. Anak-anak dibekali sikap disiplin sejak dini.

\section{c. Penyuluhan Bahaya Narkoba}

Kegiatan ini dilakukan dengan tujuan agar anak-anak khususnya dikalangan remaja mengerti dan mengetahui hukum apa saja apabila mereka masuk kedalam dunia narkoba. Hal ini juga menarik kesadaran remaja bahwa mengkonsumsi narkoba itu bahaya dan bisa dikenai hukum undangundang.

\section{d. Penyuluhan Kenakalan Remaja}

Kegiatan ini dilaksanakan guna menumbuhkan kesadaran remaja bahwa kenakalan remaja sangat merugikan untuk dirinya sendiri dan juga lingkungan. Diberikan dan dijelaskan beberapa contoh mengenai kenakalan remaja supaya 
mereka tahu apa saja yang seharusnya tidak boleh dilakukan agar tak membuat lingkungan disekitarnya resah.

\section{e. Bimbingan Belajar}

Merupakan kegiatan belajar mengajar yang bertujuan untuk membantu para siswa yang sebelumnya merasa kesulitan belajar dan mengerjakan tugas sekolah.

\section{f. Pelatihan}

Pengoperasian

\section{Komputer}

Kegiatan ini dilaksanakan untuk memperkenalkan kepada anak-anak dalam menggunakan Komputer. Contohnya: mengetik menggunakan Ms. Word dan mengoperasikan paint.

g. Membantu mengajar di SD dan di Paud

Kegiatan ini dilakukan guna mengabdi pada sekolah-sekolah yang membutuhkan atau kekurangan tenaga pengajar.

\section{h. Taman Pendidikan Al-Qur'an}

Kegiatan ini dilaksanakan agar anak-anak diberi asupan yang lebih luas lagi mengenai agama islam. Tak hanya membaca AlQur'an/Iqro, kami juga memberikan beberapa dongeng mengenai kisahkisah nabi.

\section{i. Santunan Yatim \& Jompo}

Kegiatan ini dilaksanakan untuk menumbukan kesadaran bahwa berbagi kepada orang-orang yang membutuhkan itu perlu dan rasa syukur karena telah diberikan kehidupan yang serba cukup.

\section{j. Pelatihan Kkreativitas UMKM} Pemberdayaan Masyarakat

Hal ini dilakukan untuk menambah perkenomian warga khususnya pada ibu rumah tangga yang tidak bekerja. Kreativitas ibu-ibu sangat diperlukan dalam kegiatan ini, dengan memberi contoh bagaimana cara memanfaatkan kain bekas ibuibu diajari untuk membuat bros yang patut untuk dijual.

\section{Program Fisik}

\section{a. Renovasi Pos Ronda}

Kegiatan ini untuk memberpaiki pos ronda yang telah didirikan oleh warga. Mengecat pos ronda juga dilaksanakan guna menyambut hari kemerdekaan.

\section{b. Senam Sehat}

Kegiatan ini dilaksanakan guna menumbuhkan kesadaran warga bahwa menjaga kesehatan dan kebugaran tubuh itu sangat penting.

c. Kegiatan hari kemerdekaan

Kegiatan ini diisi dengan lombalomba yang diikuti oleh warga setempat. Mulai dari anak-anak hingga lansia sangat antusias dengan kegiatan ini. Kegitan ini bertujuan untuk memeriahkan hari kemerdekaan dan rasa syukur kepada pahlawan yang telah gugur.

d. Pemasangan Plang Jalan

Kegiatan ini dilakukan dengan tujuan untuk memberi informasi tentang nama gang setempat agar orang-orang tidak kesulitan dalam mencari alamat.

\section{Divisi Pendidikan}

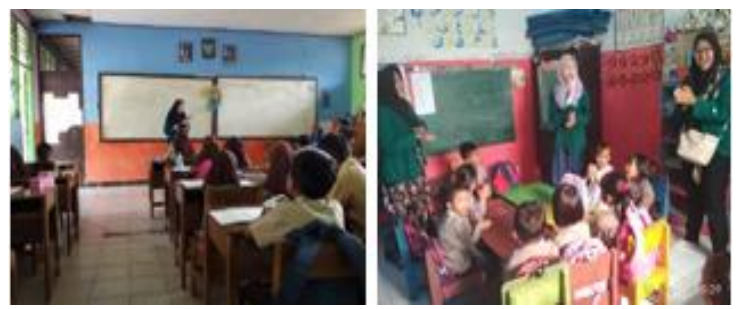

Membantu Mengajar di SDN Tapos 3 

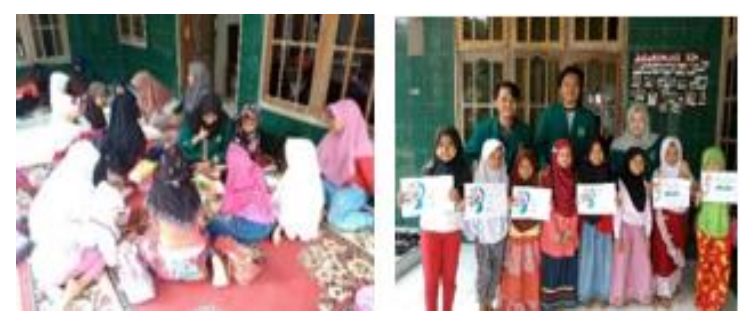

Membantu Mengajar di Paud Tunas

Harapan
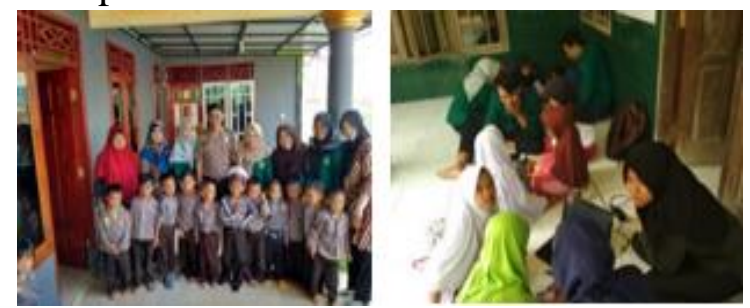

TPQ

Penyuluhan Kenakalan Remaja di MTS Majmaul Bahrain

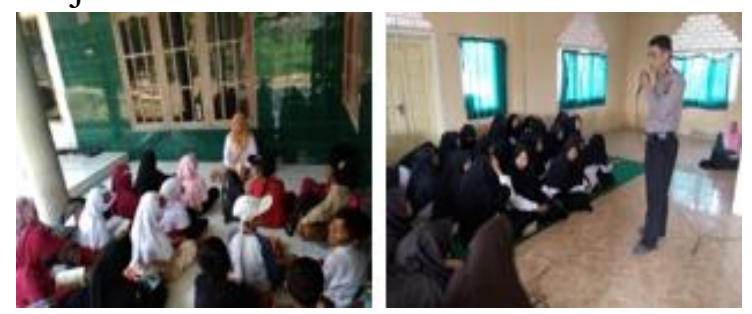

Penyuluhan Polisi Sahabat Anak di Paud Tunas Harapan

Pelatihan Pengoperasian Komputer

Bimbel (B.Inggris \& MTK)

\section{Divisi Kesehatan}
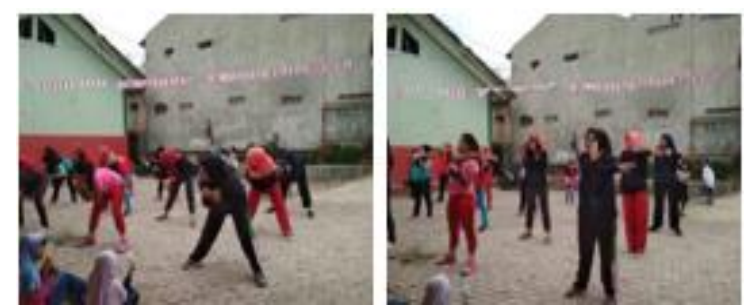

Kegiatan Senam Sehat
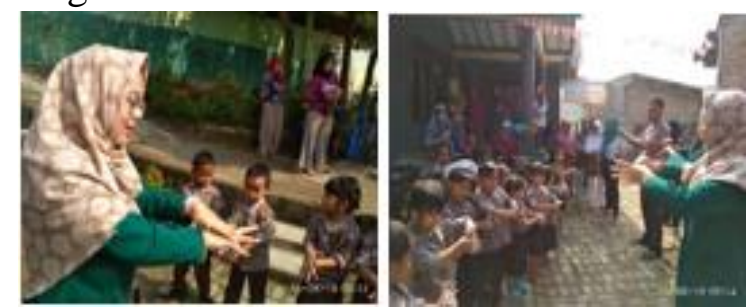

PHBS (Cuci Tangan)

\section{Divisi Hukum}

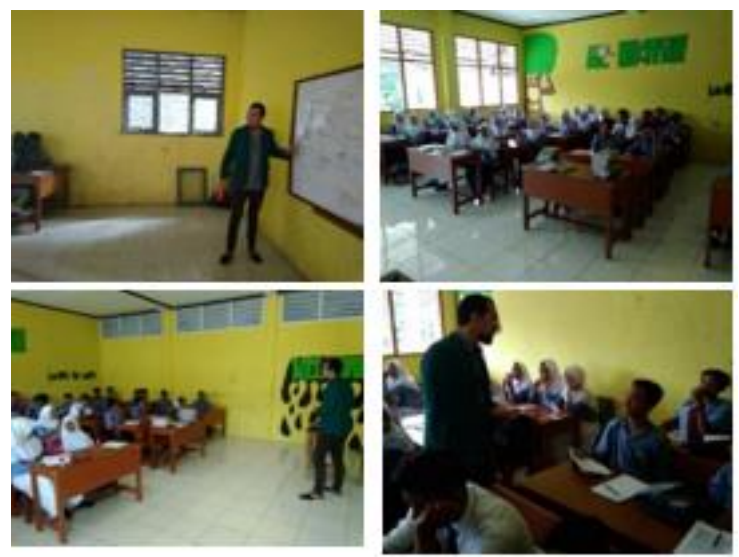

Penyuluhan tentang Bahaya Narkoba dan Hukum Pidana Narkoba

\section{Divisi Ekonomi}

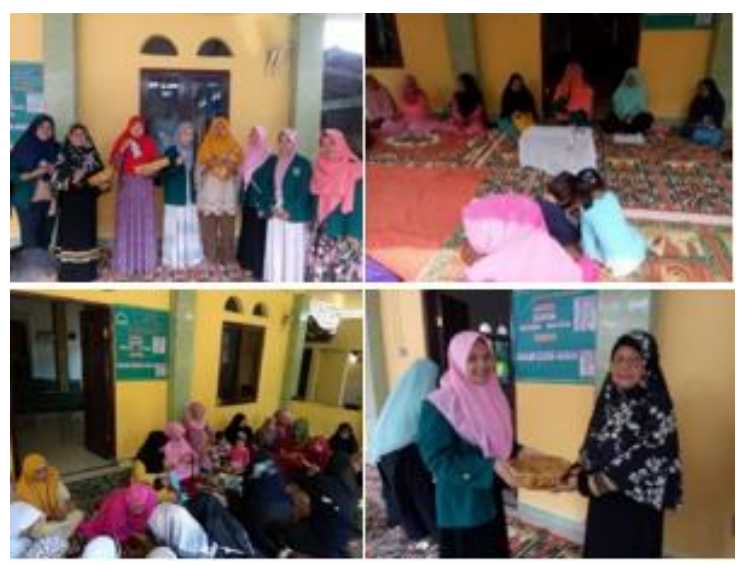

Pelatihan dan Penyuluhan UMKM

\section{Divisi Lingkungan}

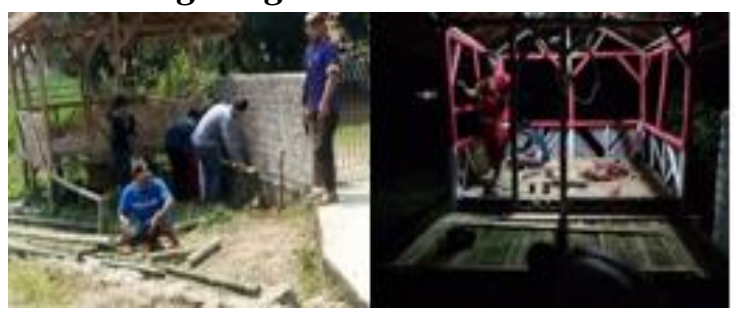

Renovasi Pos Ronda

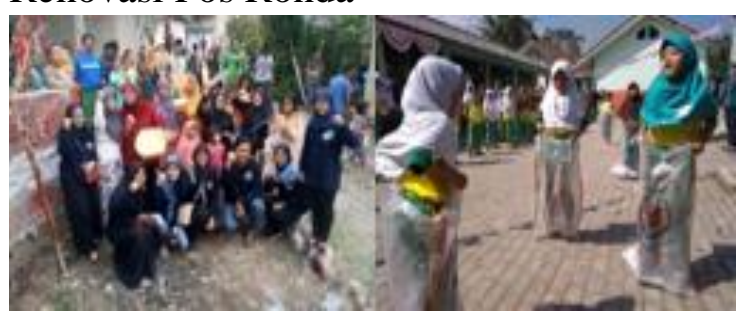

Memperingati Hari Kemerdekaan 


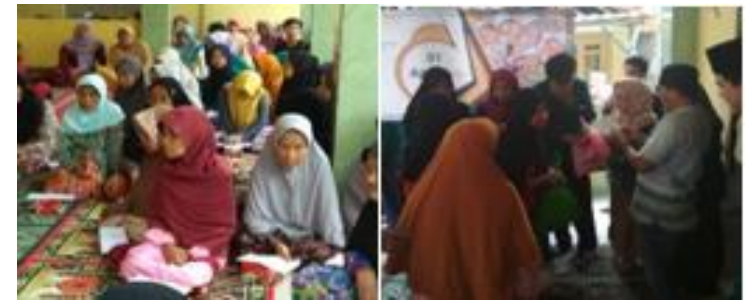

Santunan Yatim \& Jompo

Pemasangan Plang Jalan

\section{KESIMPULAN}

Kuliah Kerja Nyata (KKN) sangatlah bermanfaat bagi mahasiswa, sebagai sarana untuk lebih mengenal kehidupan bermasyarakat dan sebagai ajang untuk mengaplikasikan ilmu yang telah di dapat selama menempuh pendidikan di kampus. Sehingga ilmu yang kami dapatkan selama ini dapat berguna dan bermanfaat bagi masyarakat. Berdasarkan evaluasi dari kegiatan KKN kelompok 07 yang dilakukan di Desa Tapos 2 Kecamatan Tenjolaya Kabupaten Bogor berjalan lancar serta antusias dan sambutan masyarakat pun cukup baik dan masyarakat sangat terbuka dengan kami sehingga program kerja yang kami telah rencanakan dapat terealisasikan dengan presentase sekitar 80\%-90\%. Mengingat adanya permasalahan yang ada di lingkungan masyarakat RW. 04 Desa Tapos 2, Kec. Tenjolaya Kab. Bogor diantaranya;

a. Permasalahan di Bidang Pendidikan: 1) Masih kurangnya kesadaran warga untuk melanjutkan pendidikan anak-anak mereka ke tingkat pendidikan yang lebih tinggi. Penanggulangannya:

Memberikan penjalasan kepada warga bahwa pendidikan itu penting.

b. Permasalahan di Bidang Kesehatan: 1) Kurangnya kesadaran masyarakat untuk berprilaku hidup sehat dan bersih sejak dini. 2) Kurangnya rasa antusias warga terhadap penyuluhan yang berkaitan dengan kesehatan. Penanggulangan: 1) Dilaksanakannya penyuluhan kesehatan tentang Perilaku Hidup Sehat dan Bersih (PHBS) Cuci Tangan yang khususnya dikenalkan pada anak-anak paud. 2) Diperlukan metode baru dalam menyampaikan penyuluhan agar menarik rasa antusias warga serta memberi penjelasan bahwa menggunakan/membuat kartu jaminan kesehatan itu tidak sulit.

c. Permasalahan di Bidang Ekonomi: 1) Masih kurangnya kesadaran warga untuk berwirausaha. Penanggulangannya : 1) Mengadakan penyuluhan tentang UMKM kepada warga agar mampu meningkatkan kreativitas warga dalam memanfaatkan barang bekas menjadi barang yang bisa dijual, contohnya membuat bros dari kain yang sudah tidak terpakai namun masih bagus.

d. Permasalahan di Bidang Lingkungan: 1) Masih kurangnya kesadaran warga untuk memperbaiki pos ronda yang perlu untuk direnovasi. 2) Tidak Tersedianya Plang nama. Penanggulangannya: 1) Membuat program renovasi pos ronda dan mengecat pos tersebut supaya kondisinya bisa lebih baik dari sebelumnya. 2) Membuat plang jalan. 


\section{SARAN}

Dari hasil pelaksanaan KKN kelompok 07 di Desa Tapos 2 Kecamatan Tenjolaya kabupaten Bogor ada beberapa rekomendasi dan saran yang mungkin dapat ditindak lanjuti kedepannya agar lebih baik lagi;

a. Dukungan dan perhatian dari aparat Kelurahan/Desa sudah baik, namun perlu di tinggkatkan lagi.

b. Harus terus dikembangkannya kreativitas warga yang mungkin bisa menjadi cara yang jitu untuk meningkatkan ekonomi masyarakat.

\section{REFERENSI}

Administrasi profil Desa Tapos 2

Buku panduan KKN Universitas Ibn Khaldun Bogor

Chambers, R. 1996. Participatory Rural Appraisal: Memahami Desa Secara Partisipatif. Oxfam - Kanisius. Yogyakarta.

http://www.ilmuternak.com/2015/02/meto de-pemberdayaan-masyarakat-rrapra.html

http://nasutionnursittah.blogspot.com/2017 /01/metode-metode-pemberdayaanmasyarakat.html

20932-ID-pengembangan-metodepemberdayaan-masyarakat-dalampengendalian-vektor-demamberd.pdf 